\title{
Childhood TdT Negative Acute Lymphoblastic Leukemia
}

National Cancer Institute

\section{Source}

National Cancer Institute. Childhood TdT Negative Acute Lymphoblastic Leukemia. NCI

Thesaurus. Code C114596.

TdT negative acute lymphoblastic leukemia that occurs during childhood. 